\title{
LA SILLERÍA DE LA CATEDRAL DE SEGOVIA EN LA EVOLUCIÓN DE LOS CONJUNTOS CORALES HISPANOS
}

\author{
María Dolores TeiJeira Pablos ${ }^{1}$ \\ Universidad de León \\ FERnANDO Villaseñor Sebastián $\dagger^{2}$ \\ Universidad de Cantabria
}

\begin{abstract}
Dentro del amplio y significativo grupo de sillerías de coro de la Castilla tardogótica, la de la catedral de Segovia constituye una de los más interesantes. Esta singularidad se debe a que se trata de uno de los conjuntos corales más antiguos conservados en el reino y porque además se configura como un eslabón fundamental en la evolución de las sillerías anicónicas posteriores, entre las que podríamos considerarla un claro ejemplo de madurez a pesar de su temprana fecha. La documentación conservada sobre su construcción, inédita hasta el momento, nos permite reproducir su proceso constructivo y acercarnos a la complejidad de uno de los pocos conjuntos conservados de mediados del siglo $\mathrm{XV}$, momento clave en la evolución estructural e iconográfica de este tipo de obras, en el que esta sillería jugó un papel fundamental.
\end{abstract}

Palabras clave: Catedral de Segovia; Sillería de coro; Estalo; Juan Arias Dávila; Enrique IV de Castilla.

\section{THE CHOIR STALLS OF THE CATHEDRAL OF SEGOVIA IN THE EVOLUTION OF SPANISH CHOIR STALLS}

Within the large and significant group of choir stalls of Late Gothic Castile that of the Cathedral of Segovia is one of the most interesting. This uniqueness is not only because it is one of the oldest choral ensembles preserved in the kingdom, but also because it is a fundamental link in the evolution of later aniconic stalls, among which we could consider it a mature example despite its early date. The documentation preserved concerning its construction, unpublished until now, allows us to reproduce its constructive process and approach the complexity of one of the few conserved groups of the mid- $15^{\text {th }}$ century, a key moment in the structural and iconographic evolution of this type of work, in which these choir stalls played a fundamental role.

Key words: Cathedral of Segovia; Choir stalls; Stall; Juan Arias Dávila; Enrique IV de Castilla.

Cómo citar este artículo / Citation: Teijeira Pablos, María Dolores / Villaseñor Sebastián, Fernando (2019): "La sillería de la catedral de Segovia en la evolución de los conjuntos corales hispanos". En: Archivo Español de Arte, vol. 92, núm. 366, Madrid, pp. 127-144. https://doi.org/10.3989/aearte.2019.09.

Durante el siglo XV las sillerías corales vivieron un momento de evidente esplendor cifrado por una parte en el aumento del número de obras construidas, dentro de un clima general de renovaciones, ampliaciones y mejoras de estos muebles, y por otra, en una mayor ambición de los encargos, lo que derivó en estalos más complejos y suntuosos que sufrieron una clara evolu-

\footnotetext{
1 md.teijeira@unileon.es / ORCID iD: http://orcid.org/0000-0003-3178-4306.

2 ORCID iD: http://orcid.org/0000-0002-1509-0366. Fallecido el 15 de abril de 2019.
} 


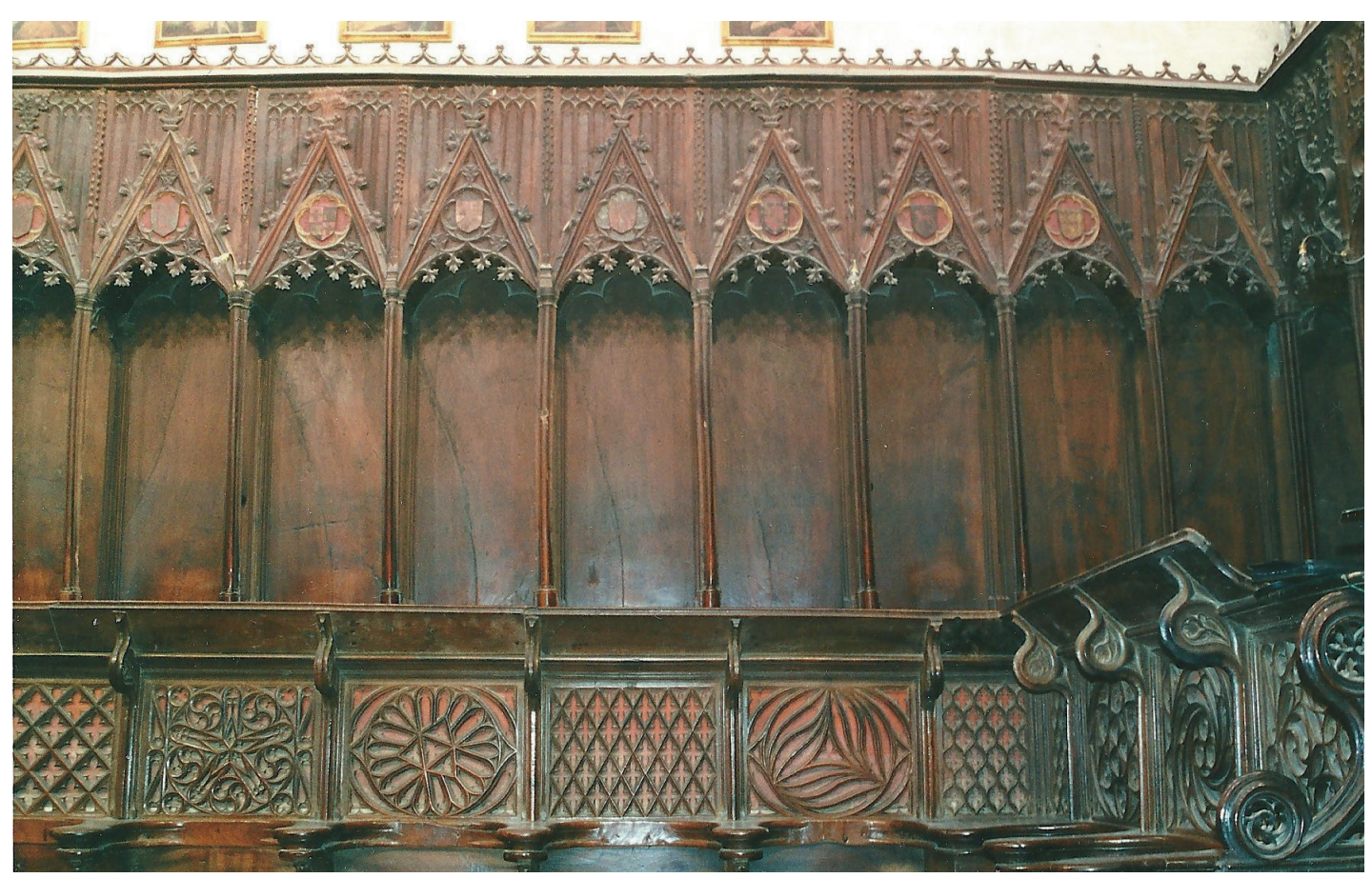

Fig. 1. Sillería de la Catedral de Palencia. Fotografía de María Dolores Teijeira.

ción estructural e iconográfica durante todo el siglo. Esta evolución fue determinante ya que de ella saldrían los modelos de sillería que se utilizarían durante toda la época moderna ${ }^{3}$.

Este proceso evolutivo partió de los conjuntos de los siglos XIII y XIV, que no conocemos bien en el reino castellano por la escasez de restos conservados, pero que, a la vista de estos, debieron ser estructuralmente simples y de talla basada en motivos geométricos y vegetales, y que se han vinculado de manera genérica al trabajo de artífices mudéjares o que utilizaban diseños de tradición islámica. Esta tendencia comenzaría a cambiar en la primera mitad del siglo XV, a partir de una serie de conjuntos corales catedralicios, de los que el más antiguo conservado es el palentino $^{4}$ (fig. 1), que experimentaron con una serie de estructuras, algunas nuevas, otras derivadas de las tradicionales, que llevarían a la tipología a una madurez estructural que aprovecharon los grandes conjuntos, anicónicos o figurados, de la segunda mitad de siglo. En esta evolución, la sillería de la catedral de Segovia tuvo un papel fundamental que pretendemos destacar a través del análisis detallado tanto de la propia obra como de su proceso constructivo, que podemos reconstruir gracias al estudio de la documentación conservada e inédita hasta el momento.

\section{La reconstrucción documental del proceso constructivo de los estalos y del acondicionamiento del espacio coral}

Durante el siglo XV la primitiva catedral segoviana vivió un proceso de reforma global que intentó actualizar y mejorar el antiguo edificio románico, que no debía estar en buen estado ade-

\footnotetext{
${ }^{3}$ Este artículo se ha elaborado en el marco de los proyectos de investigación Promoción artística y cultura cortesana en Castilla durante los reinados de Juan II y Enrique IV (1405-1474) (HAR2017-82170) y El patronazgo artístico en el reino de Castilla y León (1230-1500). Obispos y catedrales II. (HAR2017-88045), financiados por el Ministerio de Ciencia, Innovación y Universidades y Fondos Feder.

4 Teijeira, 2001; Alonso, 2015.
} 


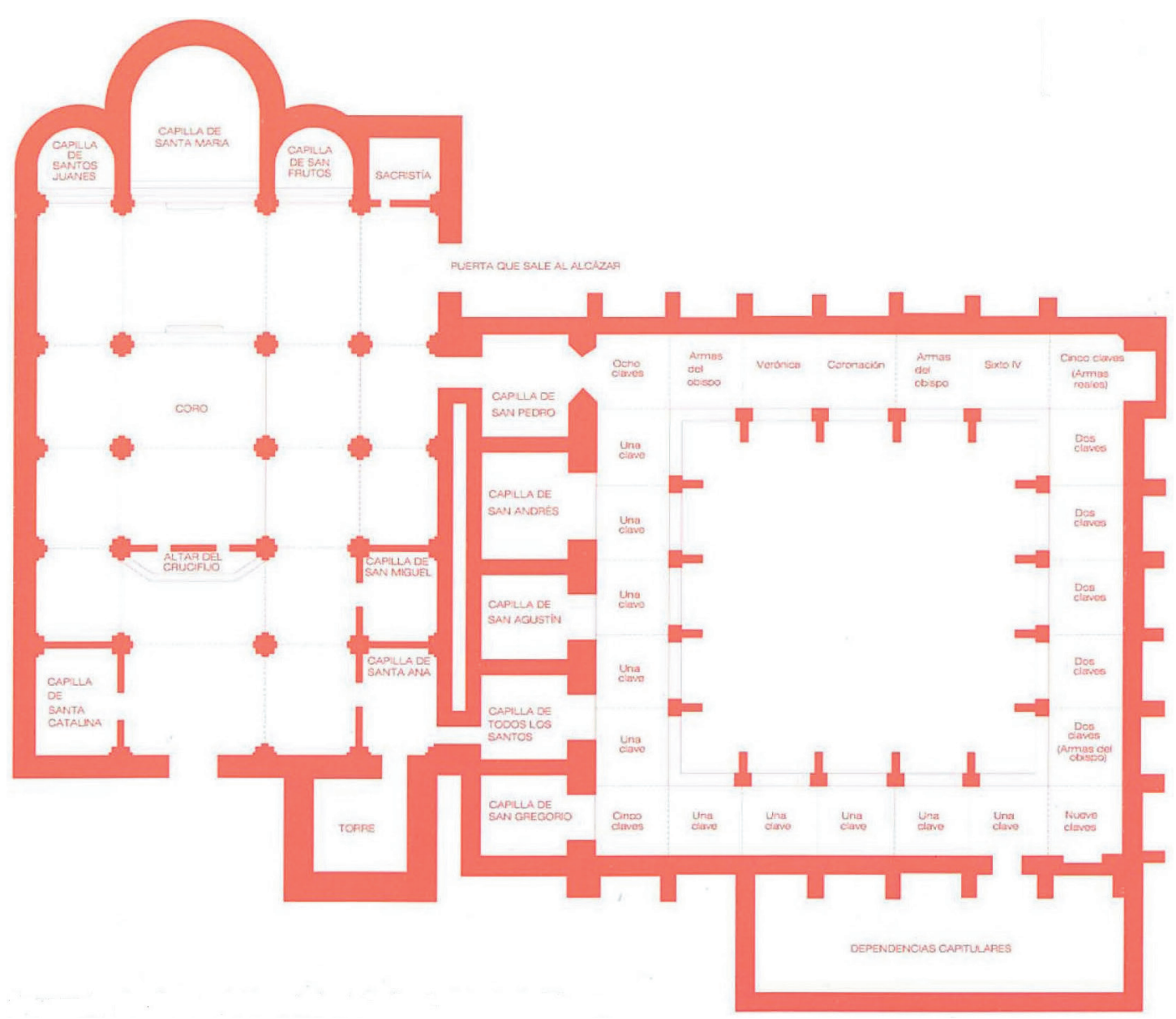

Fig. 2. Planta de la Catedral románica de Segovia con la ubicación del coro. En López, 2006: 23.

más de ser demasiado pequeño (fig. 2). Las primeras noticias de obras en la catedral —cabecera y crucero- parecen ser de $1436^{5}$, y desde 1455 se constata cierta actividad, con bulas de diferentes papas para promover la visita a la catedral y dejar limosna para la obra, a cambio de indulgencias ${ }^{6}$.

Parece haber habido un deseo de mejora de un templo antiguo, obsoleto e insuficiente, espacial, estructural y artísticamente, quizá acentuado por el interés manifestado por el rey Enrique IV de trasladar la catedral, aunque dicho traslado no pudo hacerse efectivo hasta más tarde ${ }^{7}$.

Dentro de estas mejoras, que comenzaron por la cabecera y crucero de la catedral vieja, se incluiría el coro, de cuya ubicación, cronología y aspecto previos no tenemos apenas noticias. Lo más probable es que estuviera en el mismo lugar en el que se ubicaría el nuevo conjunto y que parece haber sido la nave central, ya que la documentación recoge, como era habitual, la exis-

\footnotetext{
5 Según estatuto del obispo y cabildo de 11 de julio de ese año los notarios del cabildo debían contribuir con pagos, de su cargo, a la financiación de las necesidades de la fábrica y a las obras que se estaban haciendo en la capilla mayor y las que se tendrían que hacer para evitar la ruina del claustro. Estatuto entre obispo y cabildo, 11 de julio de 1436, Archivo de la Catedral de Segovia (ACS), Sig. 15-14. Sanz, 1988: 95.

${ }^{6}$ Calixto III en 1455; Pablo II en 1465; el cardenal Rodrigo de Borja, como vicecanciller y legado apostólico, en 1473; el papa Inocencio VIII en 1490 y Alejandro VI en 1492. Sanz, 1988: 103, 109 y 113; López, 2006: 28 respectivamente.

7 Soto, 2005: 215-220.
} 
tencia de dos "coros", el mayor, en torno al altar, que estaría en el ábside central, y un coro menor o coro de las horas, donde se encontrarían los estalos ${ }^{8}$. La diferenciación de estos dos espacios indica claramente que el conjunto coral no podía estar en la cabecera, lo que por otra parte hubiera sido difícil en el edificio románico. Es muy posible que, como ocurría en otros edificios similares, el coro de las horas fuera pequeño para el número de capitulares y poco adecuado $^{9}$, por lo que su renovación sería una prioridad si el deseo del cabildo era modernizar el templo, objetivo que cumplirá con creces el nuevo conjunto coral.

La nueva sillería se comenzó en 1458, en tiempos del obispo Fernando López de Villaescusa, o Fernando López de la Orden (1457-†1460), persona muy ligada a la catedral previamente y que debió residir regularmente, después de los episcopados de Lope de Barrientos (1438-1441), Juan de Cervantes (1441-1449) y Luis de Acuña (1449-1456), obispos todos ellos de escasa residencia y que continuaron su carrera eclesiástica en otras sedes ${ }^{10}$. El obispo Villaescusa, sin embargo, había sido canónigo en la catedral y ocupado el cargo de tesorero catedralicio al menos desde $1440^{11}$; fue también capellán mayor de Enrique IV ${ }^{12} \mathrm{y}$, entre $1455 \mathrm{y}$ 1457, obispo de Coria. Desconocemos la implicación de Villaescusa en el proceso de reforma y mejora del templo segoviano, aunque su vinculación a la catedral durante más de veinte años parece indicar, en buena lógica, que hubiese intervenido de algún modo en el inicio de las obras catedralicias, especialmente desde su cargo de tesorero, que le pondría en contacto directo con las cuestiones de financiación y, ya en su etapa de prelado, como responsable de la adecuación funcional del templo.

El único dato conservado que lo vincula a las obras emprendidas en la catedral lo hace directamente con la realización de la sillería coral, para la que, el viernes 3 de agosto de 1459, recibió el cabildo “... vn libramiento del señor obispo de diez mill maravedís que libró para las sillas del coro pagados en fin del mes de setiembre primero" ${ }^{13}$. Aunque no es una cantidad excesivamente elevada, esta entrega, al principio de la obra, supondría una aportación significativa para su puesta en marcha y demuestra claramente un interés del obispo por los estalos que, ante la falta de otros datos y de cualquier huella en el conjunto, no es posible matizar más.

La realización de las nuevas sillas se inició en septiembre de 1458, cuando se firmó el correspondiente contrato entre el cabildo segoviano y los maestros Pedro de Palencia y Juan, nombrados en la documentación como entalladores y compañeros, lo que podría suponer el establecimiento de algún tipo de acuerdo entre ellos para contratar, y realizar, obras conjuntamente (fig. 3). De este documento, que no parece haberse conservado en el archivo, quedó constancia en el correspondiente libro de fábrica, que constata igualmente el precio en el que se cerró la obra: 110000 maravedís $^{14}$, cuyos pagos fueron registrándose en los años siguientes. Así, al cerrar el año económico en agosto de 1459, se recogen los 48024 que "...tiene dados a los maestros de las sillas..."15, en el mismo mes de 1460 otros $52025^{16}$ y en agosto de 1461 varios pagos que

\footnotetext{
${ }^{8}$ En 1459 se arregló un cerrojo de este coro, denominado "menor". Libro de Fábrica 1458-1475, 8 de agosto de 1459, ACS, C-201, fol. 86r. Este libro no estaba foliado en origen, por lo que citaremos siempre por la foliación moderna a lápiz.

9 En 1258 el obispo Raimundo de Losana (1249-1259) había establecido que el cabildo estuviese compuesto por 40 canónigos, 10 racioneros y 20 medios racioneros. Este número debió permanecer bastante estable en los siglos siguientes, ya que el Memorial de Pantigoso recogía, en 1523, 69 capitulares. Sanz, 1967: 183 y 195 respectivamente.

${ }^{10}$ Las escasas donaciones de estos obispos a la sede segoviana en Villaseñor, 2018: 208; Teijeira, 2018a: 285 y López, 2006: 29.

${ }^{11}$ En ese año asistió, como tesorero de la catedral, al sínodo celebrado en Turégano por el obispo, Lope de Barrientos. García, 1993: 383.

12 Como tal gestionó, en 1447, la solicitud del rey de la ermita del Parral, que pertenecía al cabildo catedralicio, para fundar un monasterio. Colmenares, 1637: cap. XXXI.

13 Libro de Cuentas 1458-1475, 3 de agosto de 1459, ACS, C-201, fol. 6v.

14 Libro de Cuentas 1458-1475, septiembre de 1459, ACS, C-201, fol. 83r.

15 Libro de Cuentas 1458-1475, 30 de agosto de 1459, ACS, C-201, fol. 86v.

16 Libro de Cuentas 1458-1475, 25 de agosto de 1460, ACS, C-201, fol. 91v. Con posterioridad se añadió otro pago de 25 maravedís (fol. 92v.).
} 


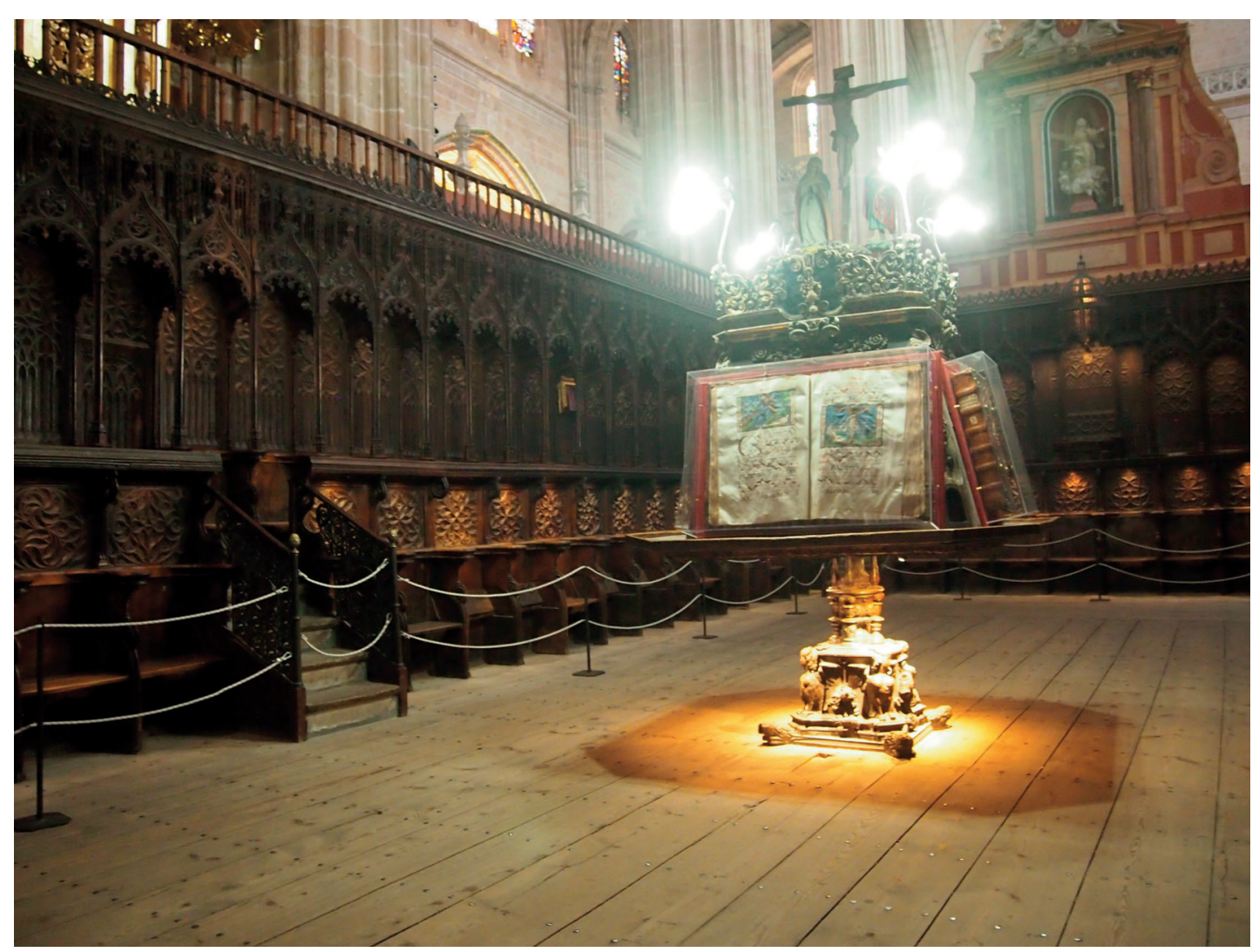

Fig. 3. Sillería de la Catedral de Segovia. Vista general. Fotografía de los autores.

completan los 51000 maravedís de la tercera anualidad ${ }^{17}$, arrojando un total de 151049 , que supera largamente la cantidad contratada inicialmente, sin que sepamos la razón de esta desviación, que se recoge junto con el último pago de 1461, afirmando que Maestre Juan “...finca contento e pagado de çiento e çinquenta e vn mill maravedís que el dicho Maestre Juan avia de aver acabado el coro segúnd está por cartas de pago"18.

La cantidad, aunque no elevada, no sería despreciable, especialmente para unos entalladores que trabajaban en un conjunto sin apenas figuración; pensando en las aproximadamente 90 sillas que debió tener en total, el precio final por silla rondaría los 1500 maravedís, incluyendo rincones, puertas y escaleras.

17 Libro de Cuentas 1458-1475, 10 de agosto de 1461, ACS, C-201, fols. 99v. y 100. Aunque se cita a ambos entalladores en los pagos de los tres años solo se menciona a Maestre Juan en los pagos concretos de 1461, quizá por muerte de Pedro de Palencia, ya que su hijo Juan sí continuó trabajando en la obra.

18 Libro de Cuentas 1458-1475, 21 de agosto de 1461, ACS, C-201, fols. 99v. y 100r. También carta de finiquito en fol. 230v. con la misma cantidad (7 de septiembre de 1461). Además, el 10 de octubre se recompensó “...a Maestre Juan e a sus criados" con un yantar (fol. 102r.) y el 1 de enero de 1462 se dio un aguinaldo a sus "moços" (fol. 104v.). Los pagos a los maestros se recogen en el mismo libro, a partir del fol. $227 \mathrm{v}$. y hasta el 230r., mensualmente, comenzando el 7 de febrero de 1459, cuando "se otorgaron por contentos" con el primer pago de 4000 maravedís "para el primero mes que empieçan a labrar", aunque la cantidad, que se cita en ocasiones como salario del mes, no es siempre la misma. En ocasiones se menciona solo a uno de los dos entalladores, en otras a los dos, en otras incluso a algunos de sus "criados" que aparecen en ocasiones como testigos. En julio de 1460 les dan los 4000 del salario mensual y otro tanto por madera y bisagras; además, en ese mismo mes se recoge — aunque tachado posteriormente — un pago de 3100 maravedís a cuenta por orden del obispo, entonces Juan Arias Dávila. A partir de 1461 los pagos se hacen más irregulares. Desde enero del 61 aparece solo recibiendo pagos Maestre Juan y es él solo el destinatario del pago de las sillas reales (fol. 230r.). 


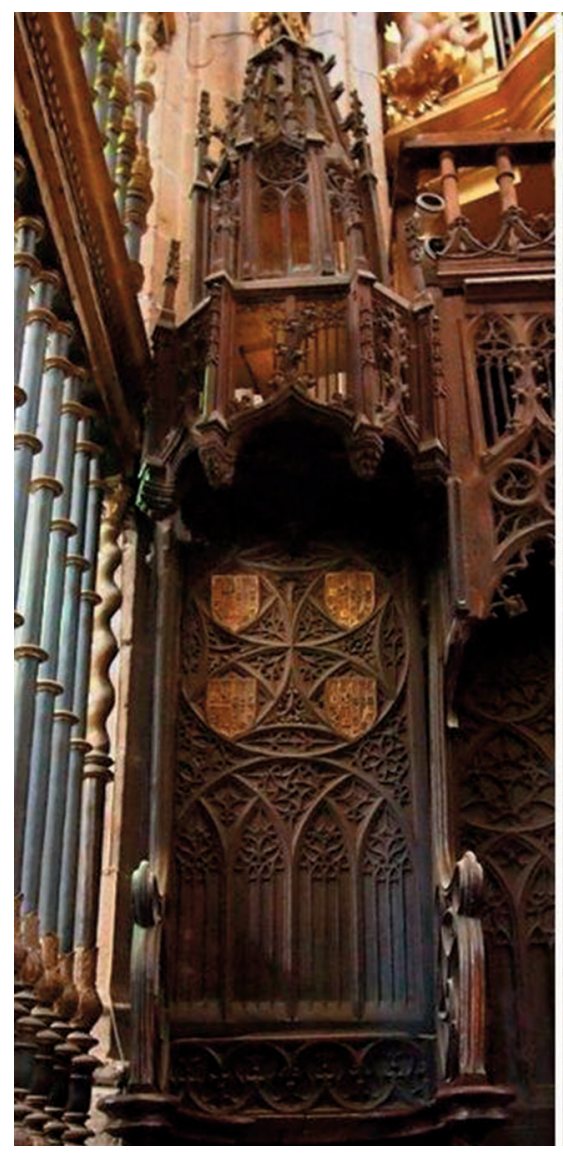

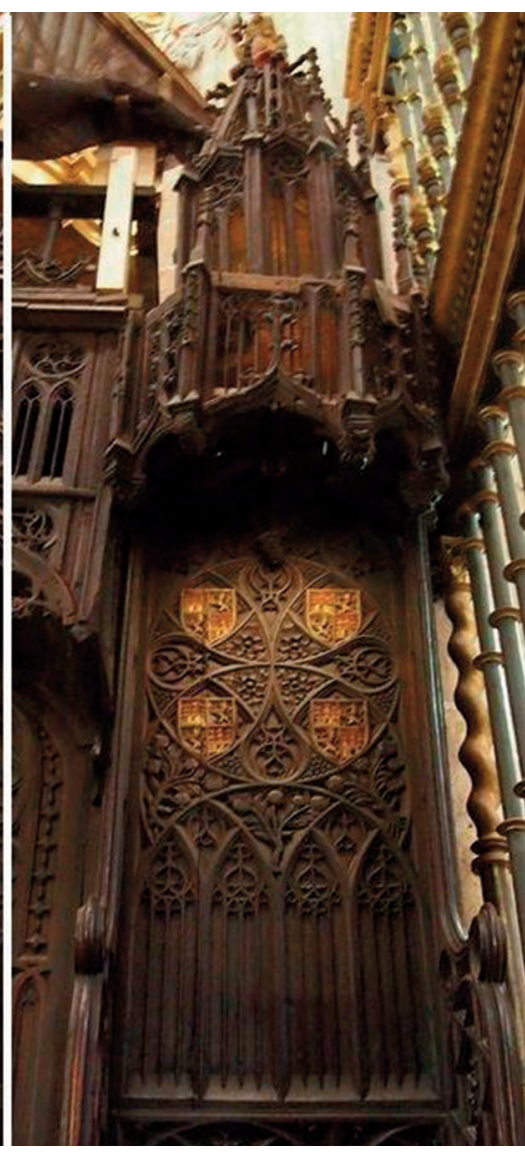

Fig. 4. Sillería de la Catedral de Segovia. Sillas de la reina (izquierda) y del rey (derecha). Fotografía de los autores.

A la cantidad mencionada debe añadirse el pago materializado en 1462 y 1463 por los dos últimos estalos, "las sillas del señor rey e la reyna", que proporcionaron a Maestre Juan 40000 maravedís adicionales ${ }^{19}$ (fig. 4). Aunque estas sillas supusieron, desde luego, un trabajo mucho mayor que cualquiera de las restantes y parecen haberle llevado más tiempo —en torno a un año de trabajo - ${ }^{20}$, el precio supera con mucho la dificultad y cantidad de talla en comparación con aquellas, lo que indica claramente la estima en que el cabildo tenía a estos estalos y el reconocimiento que con ellos quería hacerse a la dignidad regia. No se incluyó sin embargo la silla del obispo como un estalo especial, lo que no supone que no la hubiera, y de hecho sí se cita como tal, pero no parece haber tenido, en un principio, una forma y tamaño que la diferenciaran del resto de estalos (fig. 5).

La inclusión de estas tres sillas marca una importante diferencia con respecto a ejemplos anteriores. Si bien el obispo tenía la suya dentro del conjunto, siempre diferenciada del resto, y no era extraño, aunque tampoco frecuente, que hubiera estalos destinados a los reyes ${ }^{21}$, incluso a nobles; la sillería segoviana es la primera que conservamos que incluye ambos tipos, destacan-

19 Libro de Cuentas 1458-1475, agosto de 1462, ACS, C-201, fol. 107v. En este momento se le pagaron $30000 \mathrm{y}$ en marzo de 1463 los 10000 restantes (fol. 116v.).

${ }^{20}$ Libro de Cuentas 1458-1475, agosto de 1462, ACS, C-201, fol. 117v. El 12 de septiembre de 1463 se dieron estas sillas por terminadas, cuando "di a los moços de Maestre Juan el dia que acabaron las sillas del señor Rey e Reyna çien mrs para çapatos".

${ }^{21}$ En la corona de Castilla son bien conocidos los estalos regios de las sillerías catedralicias de Zamora (Teijeira, 1996: 82-84) y Plasencia (Mogollón/Pizarro, 1992: 38 y 67 y Heim, 2012: 67), claramente destacados y con tallas alusivas a sus ilustres destinatarios; pero también conocemos otros casos en los que se incluye una silla diferenciada 


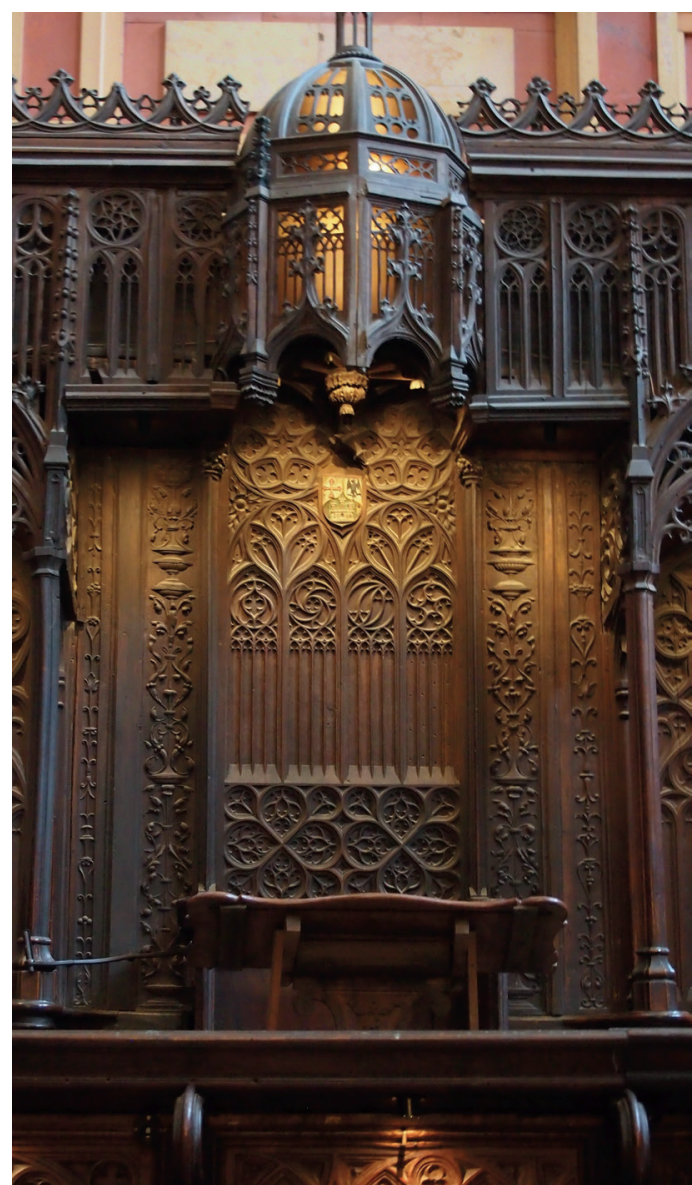

Fig. 5. Sillería de la Catedral de Segovia. Silla del obispo. Fotografía de los autores.

do la presencia regia por medio de dos estalos diferentes y situando los tres de manera claramente destacada, tanto por su tamaño, forma y elaboración, como por su ubicación en los cabos o extremos orientales - sillas regias - y en el centro del lado occidental — silla episcopal-22 (fig. 6).

El conjunto segoviano integra estas sillas especiales de manera equilibrada, favoreciendo la visibilidad de sus destinatarios dentro del coro y contribuyendo así a la difusión de una imagen de concordia entre el poder episcopal $y$ el real que estaba lejos de ser una realidad en la Segovia del siglo $\mathrm{XV}^{23}$. La presencia del estalo episcopal, presidido por el escudo del obispo Juan Arias Dávila (1460-†1497) debió obedecer a la voluntad del propio prelado, nacido en la ciudad, miembro de una familia segoviana importante y ligado previamente a la catedral como canónigo y deán, con una prometedora carrera eclesiástica por delante cuando accedió al obispado segoviano, en cuya catedral dejó claras muestras de su patronazgo artístico $^{24}$. En la presencia de las sillas reales es posible que hubiese intervenido el prelado, ya que mantenía en ese momento una estrecha relación con Enrique IV. A pesar de ello, el mayor interés lo tenía el cabildo por mantener, y reforzar, la relación con la institución monárquica, tan presente en Segovia durante toda la baja Edad Media ${ }^{25}$; pero sobre todo con Enrique IV. El monarca estaba especialmente apegado a la ciudad, pero había mantenido una relación compleja con la catedral. Por un lado, mostraba un interés, seguramente sincero, por el templo ${ }^{26}$ y por otro, un deseo de trasladarlo y eliminar de este modo los problemas seculares derivados de la cercanía física entre ambos poderes. Tanto los numerosos encargos realizados para el templo como las cantidades donadas para diversas obras catedralicias ponen de manifiesto su afecto por el mismo. Así, para la sillería coral, entregó, a través de uno de los canónigos, 30000 maravedís en marzo de $1459^{27}$.

Si poco es lo que sabemos de los posibles patronos de la obra tampoco tenemos mucha información sobre sus artífices. Pedro de Palencia y Juan trabajaron con un pequeño taller, que debía estar formado por al menos cuatro "criados" o "moços" — Pedro Martín de Obindo, Tori-

para el monarca, como en el caso de la sillería leonesa (Teijeira, 1993: 48) o la gótica, hoy perdida, de la catedral de Orense (Duro, 1964: 290).

22 Teijeira/Villaseñor, 2018.

23 López, 2006: 259.

24 López, 1998: 273-296; Bartolomé, 2004: 203-224.

${ }^{25}$ La presencia regia era clara y constante en el coro segoviano desde el siglo anterior, por la colocación en su centro del sepulcro del infante Pedro, hijo de Enrique II muerto en Segovia al caer desde una de las ventanas del alcázar, obra hoy conservada en el museo catedralicio.

26 Colmenares, 1637: Capítulo XXI, 1.

27 Libro de Cuentas 1458-1475, 20 de marzo de 1459, ACS, C-201, fol. 5v. El texto aclara además que tres de los florines entregados eran falsos, por lo que la cantidad final se vio disminuida en 499 maravedís. 


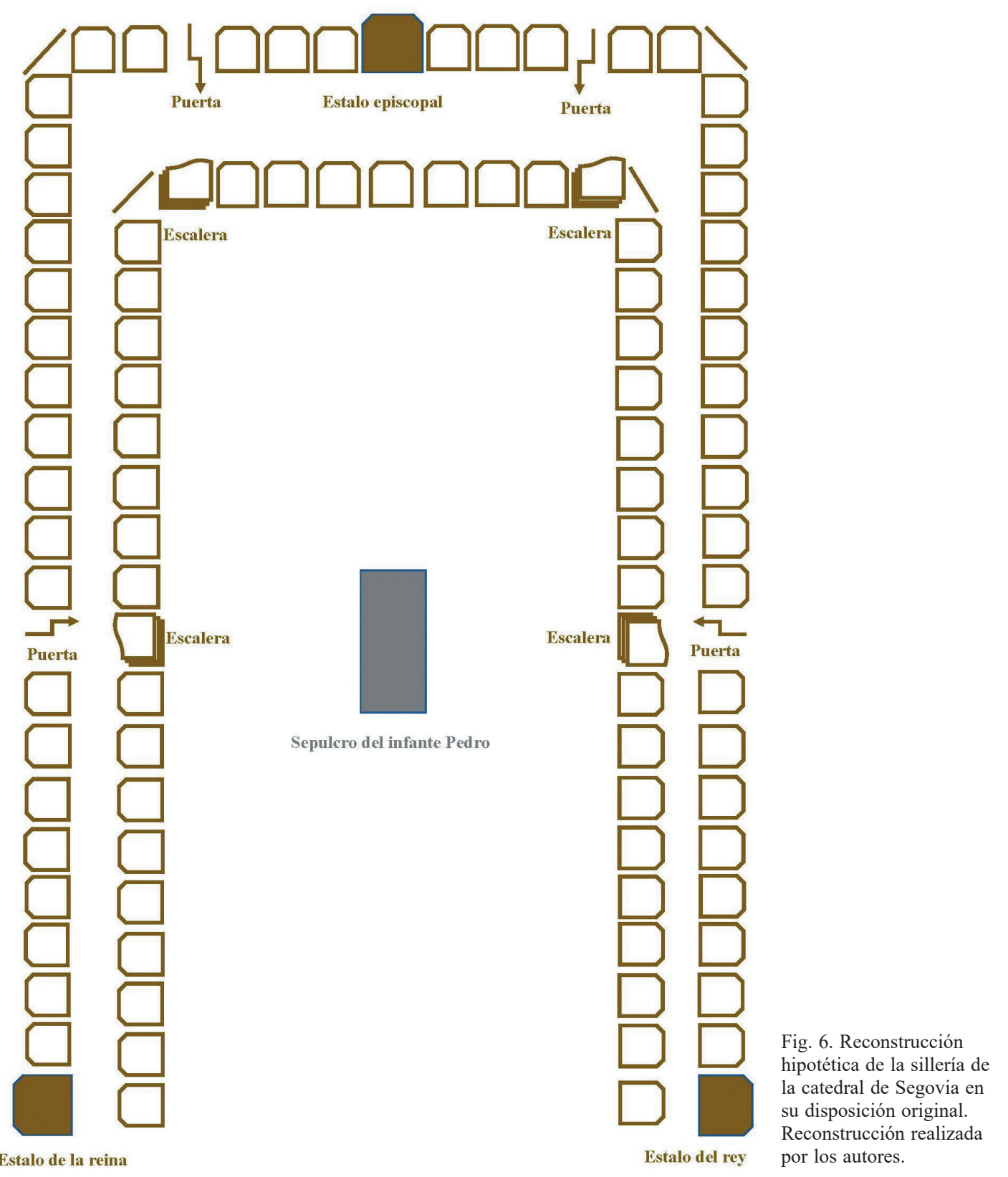

bio, Andrés y Juan de Palencia, hijo de maestre Pedro—28. La ausencia de imagineros evidencia la consecución de un conjunto anicónico, con figuración en relieve exclusivamente en los apoyamanos (fig. 7), ornándose los dorsales altos y bajos con motivos geométricos que sí entrarían dentro de los trabajos habituales de unos entalladores (fig. 8). De hecho, este tipo de motivos, resueltos de una manera muy similar, los encontramos también en otros conjuntos coetáneos y posteriores y, con anterioridad, en la sillería coral de la catedral de Palencia (fig. 1), a la que se ligaría la segoviana a través, quizá, de los citados maestros, cuyo topónimo puede indicar su procedencia geográfica y consecuentemente el conocimiento de la obra, y también de algunos

${ }^{28}$ Libro de Cuentas 1458-1475, 7 de agosto de 1461, ACS, C-201, fol. 229v. 


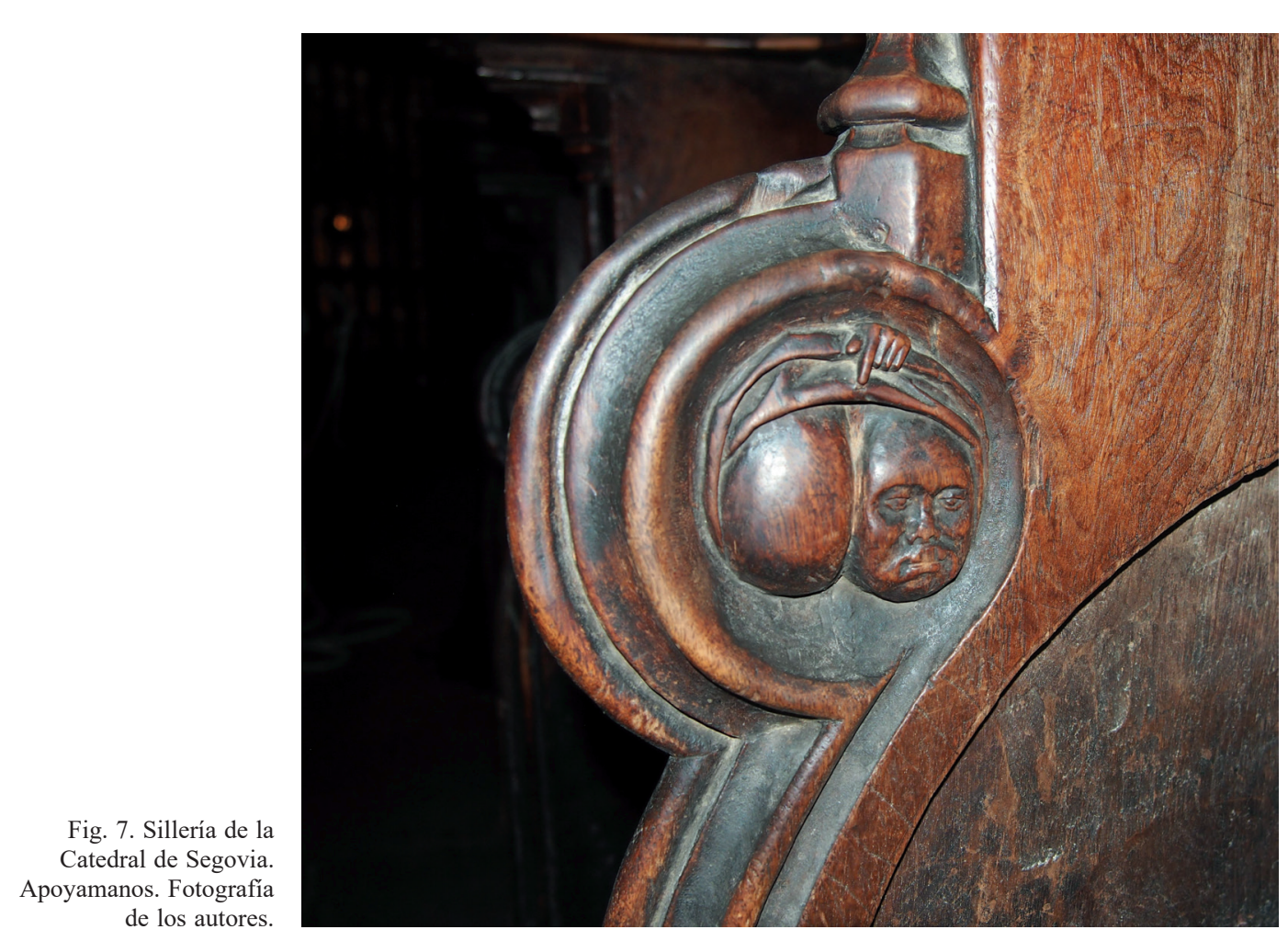

miembros del cabildo, especialmente de Fortún Velázquez de Cuéllar, deán de ambas catedrales cuando se inició la sillería segoviana.

Conseguidos y comprometidos los artistas, el cabildo se preocupó de conseguir el material para la obra, tarea que se encomendó a los mismos entalladores, encargados del traslado de la madera ${ }^{29}$.

Durante el año 1459 tenemos noticia de la entrega de diversas cantidades para la realización de la obra de la sillería, además de los 10000 maravedís entregados por el obispo Villaescusa y los 30000 que Enrique IV dio en marzo de este año. Algunos beneficiados del cabildo colaboraron también en la financiación de la obra; es el caso del arcediano de Sepúlveda, Luis Martínez, que legó 2000 maravedís que fueron entregados por su testamentario en septiembre, junto con otros 100 del cepo de la iglesia ${ }^{30}$. Finalmente, en abril de 1460 se recibieron 5000 maravedís más por parte de Diego Arias Dávila, padre del futuro obispo Juan Arias Dávila "[...] para ayuda a faser las syllas" 31 .

Estos aproximadamente 47000 maravedís suponen toda la financiación extraordinaria que ha quedado recogida en la documentación con destino a esta obra, cantidad con la que no se llegaría a cubrir ni el pago de una anualidad a los artistas, por lo que sería imprescindible la colaboración del cabildo con los fondos de la fábrica, como era habitual en este tipo de encargos.

A medida que iban trabajando los entalladores, de cuyos avances la documentación no nos aporta más datos que los pagos realizados, se iba preparando el espacio coral que debía acoger la nueva sillería. Como se ha mencionado, parece que este espacio era el mismo que había ocupado

29 Se pagó a "Mestre Pedro de Palençia e a Maestre Juan, su compañero, entalladores" una primera vez, y a Maestre Juan solo una segunda, 5000 maravedís "para en prinçipio de traer la madera para las sillas del coro". Libro de Cuentas 1458-1475, 25 de octubre de 1458, ACS, C-201, fol. 227r. Más adelante, mezclados con otros, aparecen nuevos pagos (fol. $227 \mathrm{v}$.) —en marzo de 1459 se afirma haberles pagado ya 15000 por este concepto-

30 Libro de Cuentas 1458-1475, 3 de septiembre 1459, ACS, C-201, fol. 8r.

31 Libro de Cuentas 1458-1475, 14 de abril de 1460, ACS, C-201, fols. 8v. y 89v. López, 2006: 37. 


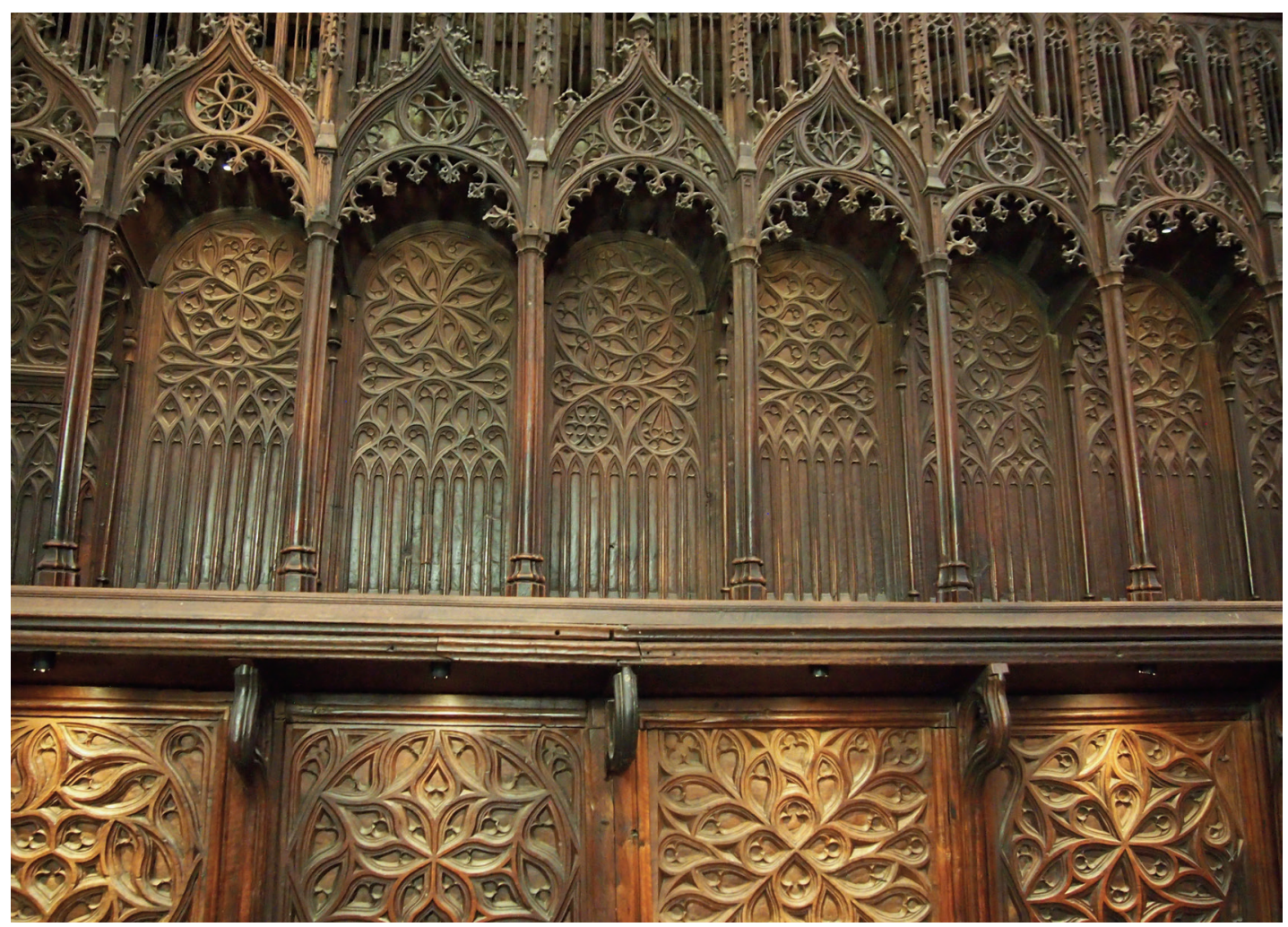

Fig. 8. Sillería de la Catedral de Segovia. Lado de la Epístola. Dorsales altos y bajos. Fotografía de los autores.

el coro anterior, ya que lo primero que se hace es quitar las sillas viejas ${ }^{32}$. Con el espacio ya despejado se preparó el pavimento para soportar el peso de la nueva sillería, lo que es igualmente indicativo de un tamaño mayor y una mayor complejidad del nuevo conjunto con respecto al antiguo, ya que se añadieron doce canes, tres en cada pilar, en la parte inferior de los cuatro pilares, dos de cada lado, "de medio del coro" ${ }^{3}$, que servirían para apoyar las vigas que soportarían el pavimento del coro. Llama la atención que solo se trabaje de este modo sobre cuatro pilares, es decir un único tramo de la nave central, lo que puede relacionarse con una sillería una quinta parte menor que la actual y por lo tanto necesitada de un espacio más pequeño que los dos tramos que hoy ocupa, pudiendo haber aprovechado una parte del pavimento anterior si este se encontraba en buenas condiciones. En cuanto al material del solado, que no se especifica en la documentación, debería ser el mismo que utilizaba el resto de la iglesia, y que seguramente era piedra; no disponemos de datos que nos permitan descartar un piso de madera ante el uso de vigas de este material como soporte, aunque no era muy frecuente en estos momentos; puede que a ello se refiera el "enforro del coro" que se llevó a cabo entre finales de noviembre y principios de diciembre de 1460, aunque por sus dimensiones no parece muy probable ${ }^{34}$.

32 Libro de Cuentas 1458-1475, 25 de junio de 1460, ACS, C-201, fol. 89v. Se comenzaron a quitar en este día y solo constan pagos de dos días al maestro de la obra, Maestro Roxo, junto con otro maestro musulmán, Aza, además de cuatro obreros un día y seis otro, por lo que no parece que la sillería anterior fuera ni muy grande ni muy compleja.

${ }^{33}$ Libro de Cuentas 1458-1475, 15 de julio de 1460, ACS, C-201, fol. 90r. Ese día se contrata esta obra con el cantero Alvar González, que debía "socavar" los pilares para poner los canes, que serían "de piedra cárdena". Esta obra supuso 1600 maravedís de coste. La mayoría de los datos referidos al acondicionamiento del espacio coral se recogen en López, 2006: 42.

${ }^{34}$ Libro de Cuentas 1458-1475, 20 de noviembre de 1460, ACS, C-201, fol. 95r. Se usaron para ello diez tablas, que costaron, con su asentamiento, 710 maravedís. 
Junto con el pavimento se iniciaron también los cerramientos laterales del coro, las "costaneras". Parece que se trabajó sobre unos cerramientos ya realizados, en los que se debieron hacer modificaciones importantes, ya que para esto se contrató a tres "oficiales de cantería", con varios peones, y en alguno de los pagos se denomina con los términos "çegar" o "tapiar", lo que debió suponer adaptar y cerrar con piedra unos elementos ya existentes ${ }^{35}$. Durante este tiempo un carpintero, Miguel, con otro oficial, hizo una escalera para encender las lámparas y dos bancos para el coro, obra de poco empeño dado el bajo precio que se les pagó, pero que indica un cierto uso del espacio ${ }^{36}$.

Además de las paredes laterales se cerró el coro, como es habitual, con un trascoro, en el que se comenzó a trabajar a la terminación de las costaneras, el 10 de septiembre, cuando se contrató, con el cantero Juan Alonso "vyscaino", "la paret que es a las espaldas del coro con el altar del Ihesu" por 950 maravedís ${ }^{37}$. El altar y retablo "del Ihesu" o del Crucifijo ya existía, dado que se documenta su desmonte del trascoro anterior y su nuevo montaje en el nuevo. El hecho de que no le quisieran dar al cantero más materiales que cal y arena podría suponer que hubiera reaprovechado la piedra del trascoro anterior, ya que se cita este material entre los pagos ${ }^{38}$, quizá para las gradas que se añadieron, probablemente para el altar que debió situarse en el centro del muro $^{39}$, flanqueado por dos puertas de madera, bajo dos arcos de piedra tallada ${ }^{40}$. En este espacio se encontraba la capilla de los obispos, donde se enterraron varios prelados segovianos, como podemos deducir del testamento de Juan Arias Dávila, que pidió ser sepultado allí con sus predecesores ${ }^{41}$.

Si asumimos que el trascoro se componía de un altar con un retablo en el centro y puertas laterales a ambos lados, la sillería adoptaría un esquema cerrado en su lado oeste, lo que apoyaría la hipótesis de la existencia, al menos desde este momento, de un estalo episcopal diferenciado del resto en el centro del lado occidental, lo que constituiría el primer ejemplo castellano conocido de sillería cerrada, modelo que tardaría aún medio siglo en consolidarse en este reino, frente a los coros abiertos que facilitaban la liturgia procesional y que debían ser mayoría en este momento ${ }^{42}$. El precedente palentino, que contaba ya con un estalo episcopal desarrollado, habría tenido en origen esta misma disposición abierta, ya que la silla del obispo está diseñada para adosarse a otro estalo por su lado izquierdo, constituyendo por lo tanto uno de los cabos occidentales del conjunto, en concreto en el lado del evangelio ${ }^{43}$. En el coro segoviano, sin embargo, se dio un paso más en la monumentalización y dignificación del estalo episcopal al otorgar al prelado un claro protagonismo dentro de este espacio.

Estas obras preparatorias, que se iban haciendo en paralelo a la realización de las sillas, indican una ampliación o mejora importante del espacio coral, un espacio mayor y más desahogado

35 Libro de Cuentas 1458-1475, Julio-agosto de 1460, ACS, C-201, fols. 90r.-91r. Para ello se compraron cantidades importantes de piedra, cal y arena, se pusieron andamios y se trabajó durante un total de 22 días, entre el 19 de julio y el 14 de agosto, cuando "çesó la obra", con un coste total de 2257 maravedís.

${ }^{36}$ Libro de Cuentas 1458-1475, 23 de julio de 1460, ACS, C-201, fol. 90r. Se les pagó por ambas obras 50 maravedís.

37 Libro de Cuentas 1458-1475, 10 de septiembre de 1460, ACS, C-201, fol. 94r. Se especifica que este precio es solo "por sus manos" y que se le daría cal y arena "e non mas". Aun así se documentan pagos a otros dos maestros canteros trabajando en el coro, necesariamente en esta obra, aunque no se especifica.

${ }^{38}$ Libro de Cuentas 1458-1475, 20 de septiembre de 1460, ACS, C-201, fol. 94r.

39 Libro de Cuentas 1458-1475, 23 de septiembre de 1460, ACS, C-201, fol. 94r. Se le pagaron además 90 maravedís porque "fiso más gradas e más largas que avía puesto". La obra del trascoro supuso un gasto total de 1250 maravedís.

40 Libro de Cuentas 1458-1475, 13 de diciembre de 1460-7 de septiembre de 1462, ACS, C-201, fols. 95v., 96r. y v., y 108v. Estas puertas, monumentalizadas por sendos arcos de piedra tallada, se comenzaron en enero de 1461 y no se terminaron hasta septiembre, entre otras cosas porque el pintor encargado de pintarlas, Fray Pedro, fue apresado y tuvieron que sustituirlo por otro, Antón, con el correspondiente sobrecoste de una obra que no debió ser menor, ya que supuso un gasto de 3675 maravedís.

${ }^{41}$ Le Flem, 1970: 35.

42 Navascués, 2013 sugiere, sin embargo, una estructura abierta para el coro segoviano, con el estalo episcopal adosado al extremo occidental del lado de la epístola.

43 Teijeira, 2001. 
que aprovecharía probablemente parte del coro anterior y que podría haber estado en los primeros tramos de la nave central ante la pequeñez del presbiterio.

De este modo, el 2 de diciembre de 1460, después de limpiarlo44, "dieron la buena entrada del coro a los entalladores" ${ }^{\prime 4}$, lo que supone seguramente que, una vez acondicionado el espacio, se podía comenzar a ensamblar los estalos que, durante los dos años previos, habrían ido realizando los maestros Pedro y Juan con su taller. Teniendo en cuenta la falta de figuración de las sillas, dos años sería tiempo más que suficiente para realizar los cerca de 90 estalos que tendría entonces el coro.

En paralelo se comenzó a trabajar en otros elementos complementarios, como los órganos ${ }^{46}$, los facistoles ${ }^{47} \mathrm{o}$ los púlpitos ${ }^{48}$, pero también se acondicionaron algunos de los libros que estarían en el coro - se encuadernaron y aseguraron con cadenas a los atriles algunos de ellos-, entre los que se citan dos breviarios, al menos dos racionales y, probablemente, una biblia, un Flos sanctorum y un salterio glosado ${ }^{49}$, además del libro de regimiento del coro $^{50}$. De este modo, la sede segoviana participaba del proceso de creación y renovación de los libros de coro que tuvo lugar en las principales catedrales y monasterios castellanos durante la segunda mitad del siglo $\mathrm{XV}^{51}$.

En el coro, sin especificar si el mayor o el menor, se colocó también una viga, de 35 pies de largo, para colgar de ella las lámparas que daban luz a esta parte del edificio, viga en la que se pintaron y doraron "los escudos de las armas reales" 52 . La iluminación especial del espacio coral, fundamental para asegurar su funcionalidad, pero también para destacar su importancia dentro del templo, comprometió a los monarcas, además, con la donación de otras dos lámparas que se hicieron entre junio y octubre de 1466 con la plata, posteriormente dorada y enriquecida con algunos esmaltes, quizás heráldicos, de un confitero y seis lámparas "que ofreció la señora reyna doña Johana"53.

La presencia regia en el coro alcanzaba de este modo un gran protagonismo, al incluir estos escudos pintados en la viga, más los probables de las lámparas y los de las sillas reales en los

44 Libro de Cuentas 1458-1475, noviembre de 1460, ACS, C-201, fol. 94v.

45 Libro de Cuentas 1458-1475, 2 de diciembre de 1460, ACS, C-201, fol. 95r. Por esta razón les pagaron 210 maravedís.

46 Libro de Cuentas 1458-1475, 1461-1463, ACS, C-201, fols. 101 r. y v. Además de los pagos al organista y al afinador la documentación recoge también diversos trabajos para acondicionar las tribunas de los órganos, mayores y menores, que debían estar sobre la portada meridional del templo, adonde Maestre Juan las había trasladado. Enrique IV encargó órganos nuevos al taller de Alfonso Díaz de Ávila, que desplazó a sus maestros a Segovia con este fin en 1462. Los órganos se asentaron en junio de 1463. López, 2006: 43.

47 Libro de Cuentas 1458-1475, noviembre-diciembre de 1460, ACS, C-201, fols. 95 r. y v. De los dos facistoles de madera que se hicieron para el coro - uno para el lado de la epístola y otro para el del evangelio, uno pequeño y uno grande - comienza a haber noticias desde principios de noviembre de 1460; en ellos trabajaron el maestro de la obra, Roxo, y su hijo, pero también un cantero - Valdovinos-. Ambos facistoles estaban recubiertos de cuero (fol.126v.)

48 Libro de Cuentas 1458-1475, 12 de agosto de 1462, ACS, C-201, fol. 107r. Se encargaron "los púlpitos donde se dice el evangelio e el epistola" a Martín de Artiaga, cantero vizcaíno, por 7000 maravedís, a los que podrían añadirse 500 más. Sobre ellos Juancho, pintor, pintó dos imágenes previamente talladas en madera, un águila para el púlpito del evangelio y un san Pablo para el de la epístola, que se asentaron el 25 de junio de 1463 (fol. 110v. y 113r. respectivamente). Estos púlpitos se confunden, desde agosto de 1464, con el "predicatorio" que hizo el maestro relojero, Grosarte, Josarte o Juyarte, ya que era de hierro (fol. 127r. y 146v.), asentado sobre un pie de alabastro (fol. 151v.).

49 Libro de Cuentas 1458-1475, 1461-1470, ACS, C-201. A finales de febrero se encuadernaron "los dos breuiarios del coro" (fol. 96v.). El 18 de junio se "adobó" "vno de los raçionales que se posieron en el coro" (fol. 99r.) y se compraron cadenas, una de las cuales era para una biblia. El 20 de julio se "guarnercieron" los otros libros citados y se compraron cadenas para ellos (fols. 99r. y v.). En 1470 se encuadernó el salterio del coro del obispo y "el libro que dicen las tablas" (fol. 168r.).

50 Libro de Cuentas 1458-1475, 25 de julio de 1462, ACS, C-201, fol. 107r. "[...] vn libro del regimiento de cómo ha de seruir el tesorero el coro e el altar e lámparas e sagrario e campanas e çera e aseyte e todas las otras cosas que pertenescen a su ofiçio" se escribió, encuadernó y encadenó en el coro.

51 Yarza, 1989: 109-112; Villaseñor, 2009: 141-283.

52 Libro de Cuentas 1458-1475, 20 de julio de 1461, ACS, C-201, fols. 99 r. y v. La viga, su trabajo y asentamiento, los cordeles para las lámparas y la talla de los escudos, con su pintura y dorado, supusieron un gasto de 620 maravedís. Todavía en enero de 1463 se estaba trabajando en ella (fol. 110r.).

${ }^{53}$ Libro de Cuentas 1458-1475, 30 de junio de 1466, ACS, C-201, fol. 50r. 


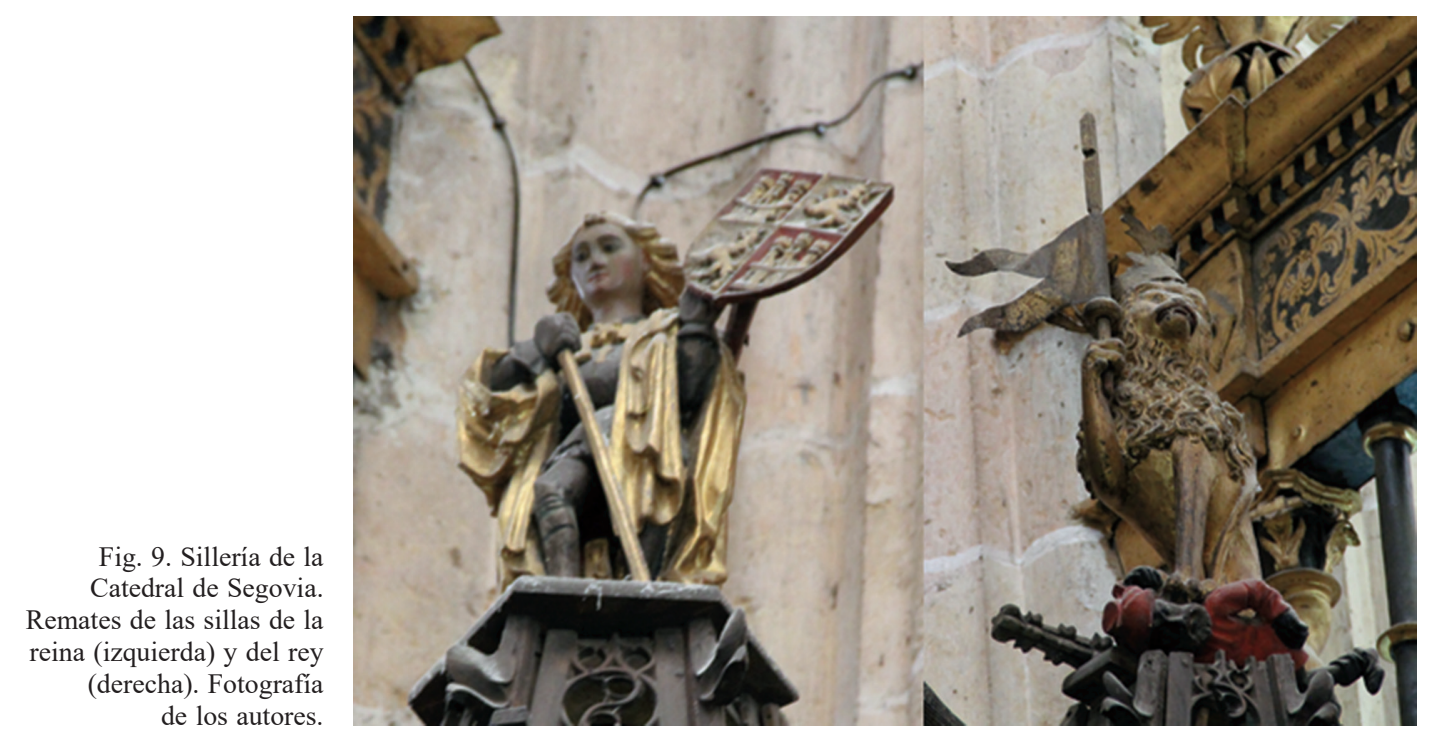

cabos, además de las alusiones a la monarquía, y específicamente a Enrique IV, contenidas en los altos baldaquinos que coronaban estas, con un león coronado portando el estandarte de Castilla y León y pisando a un musulmán tirado a sus pies en la silla del rey y un heraldo con las armas del reino en la de la reina ${ }^{54}$ (fig. 9). La colocación en el centro del espacio coral del sepulcro del infante Pedro Enríquez de Castilla ${ }^{55}$ completaría el protagonismo de la institución regia y su relación con la propia catedral.

Coincidiendo con la finalización de los trabajos complementarios del coro se realizaron las sillas reales de los cabos del coro y sus "asentamientos" o "poyos", es decir, los asientos abatibles de cada una de ellas con sus misericordias ${ }^{56}$. Con la finalización y montaje de estas, a fines de 1463 , se dio por terminada la sillería y se recompensó a sus artífices ${ }^{57}$.

A partir de aquí las noticias que tenemos de la sillería son más escasas y nos hablan de una obra ya en uso que, a pesar de ser tan reciente, empezaba a precisar algunas reparaciones y aderezos, a medida que se iba usando y se iban viendo nuevas necesidades ${ }^{58}$. De esta manera, a finales de 1466 hubo que "adobar çiertas sillas del coro", y poco después "...otras dos sillas del coro que se quebraron en la 'missa nueua' del obispo" 59 . Todavía en septiembre de 1467 hubo

54 Teijeira/Villaseñor, 2018.

55 Libro de Cuentas 1458-1475, 20 de julio de 1461, ACS, C-201, fol. 124v. El sepulcro contaba con sus propias lámparas, que ardían permanentemente y que se guarnecieron con cadenas en mayo de 1464. Además, en determinadas ocasiones se añadían otras luminarias a la tumba, como las "quatro fachas" que se pusieron en ella en la víspera de "todos santos" de 1466 (fol. 158r.).

56 Libro de Cuentas 1458-1475, 15 de marzo de 1463, ACS, C-201, Fol. 110r y 111r. Supusieron un total de 101 maravedís.

57 Libro de Cuentas 1458-1475, 12 de septiembre de 1463, ACS, C-201, fol. 117v: "di a los moços de Maestre Juan el dia que acabaron las sillas del señor Rey e Reyna çien mrs para çapatos". El 18 de noviembre "mandaron los señores dar vestuario a Maestre Juan entallador que fiso las sillas del coro conuiene saber al dicho Maestre Juan vna capa e vn sayo de fino pano de Ypres e a dos criados suyos sendas capas de fino Roal", con un coste total de 3242 maravedís (fol. $120 \mathrm{v}$.$) .$

58 Libro de Cuentas 1458-1475, 9 de enero de 1466, ACS, C-201, fol. 152r. De este modo se hicieron unos "arquetones" para los que se pusieron unos cerrojos en febrero de 1466 (fol. 157r.). Se refiere seguramente a los contenedores - de libros, velas...- que frecuentemente encontramos en algunas de las sillas bajas de los coros, como los que todavía se conservan en esta misma sillería.

59 Libro de Cuentas 1458-1475, diciembre de 1466, ACS, C-201, fols. 159v.-160r. Desconocemos qué pasó en esta misa, quizá la primera de Juan Arias Dávila como obispo efectivo, para que se rompieran dos sillas y "el façistol de fierro" (fol. 161v.), 
que "adobar vna silla del coro del obispo con tres barras de fierro e clauos e cola", "el façistol de fierro el pequeño" y la reja del coro, alargando dos barrotes de hierro de la misma "porque se caya la puerta" ${ }^{60}$. Otras operaciones habituales, como esterar el coro o limpiar las sillas, se recogen también con su coste ${ }^{61}$.

Entre estas modificaciones y adiciones destacan las encargadas por el propio obispo Arias Dávila, que adecúa su asiento con varias pequeñas obras, como la "cadena estañada que ay en ella dos brocados" que mandó poner en "vno de los dos racionales en su silla" 62 .

\section{Hacia la sillería actual: el traslado a la catedral nueva y las modificaciones del conjunto}

A pesar de la amplia documentación conservada sobre esta obra, y de la afortunada pervivencia de los estalos mismos, hay multitud de cuestiones que desconocemos con respecto a su aspecto y composición originales, ya que la sillería ha llegado hasta nosotros gracias a que fue trasladada a la catedral nueva y, con este motivo y debido también a otras circunstancias, perdió algunos estalos y se le añadieron nuevos, al menos en dos ocasiones, lo que transformó necesariamente la obra original.

En 1520 la catedral se convirtió en escenario de los enfrentamientos que tuvieron lugar en Segovia en el marco de las comunidades, quedando el coro en muy mala situación, con "las sillas del coro trastornadas y evertidas de sus lugares y muchas dellas quemadas y otras quebradas puestas por defensa y albarradas y hecho dentro y alrededor cavas, fosados, minas y contraminas"63. Quizá por esta razón y desde luego por la estrechez de la iglesia del convento de Santa Clara, adonde se trasladó el culto durante la construcción de la nueva catedral, los estalos debieron quedarse en la vieja durante casi cuatro décadas. Al avanzar la obra del nuevo templo y voltear las bóvedas del espacio coral en 1541, construyéndose un cierre temporal en 1543 para acoger el altar hasta que se rematase la cabecera, y asentándose las rejas ${ }^{64}$, se pudo trasladar la sillería, lo que sucedió el 4 de agosto de $1558^{65}$, por parte de los entalladores Bartolomé Fernández y su yerno Lucas de Lasen, a los que se pagó 130 ducados el 28 de septiembre por esta labor ${ }^{66}$. Para su ensamblado en la catedral nueva "En veynte días de setiembre pagué a Gerónimo de Enberez y Juan Gil entalladores çinquenta e vn mill e setecientos y cinquenta mrs de ocho sillas que hizieron y sentaron en el coro las quatro altas y las quatro baxas por libramiento del señor canónigo Juan Rodríguez"67. Las sillas ocuparon, como se ve actualmente, el segundo y tercer tramos de la nave central, al estar el primero ocupado provisionalmente por el altar mayor.

En el siglo XVIII, a raíz de la consagración de la catedral en 1768, se construyó un nuevo trascoro y, en relación con ello, se añadieron diez nuevas sillas en el nivel alto y ocho en el bajo, que hizo, teniendo en cuenta el estilo de las antiguas, el ebanista Fermín Huici, que añadió también el doselete de la silla episcopal ${ }^{68}$. De este modo se configuró el conjunto que podemos ver actualmente, formado por 118 estalos, 65 altos -incluidas las dos sillas reales y el trono episco-

${ }^{60}$ Libro de Cuentas 1458-1475, septiembre de 1467, ACS, C-201, fol. 165v.

${ }^{61}$ Libro de Cuentas 1458-1475, ACS, C-201. Hay varias noticias de la paja que se echaba en el suelo, bajo las esteras o alfombras, y que aislaba los pies del frío del suelo (en 1462 y 1463 respectivamente, fols. 105r. y 111r.), así como de la compra de ocho esteras "para los pies" en 1464 (fol. 130r.). Las sillas corales se limpiaron en 1470 con estopa (fol. 168r.), limpieza especial que se pagó aparte de la limpieza habitual que correspondía al perrero, quien debía también barrer y regar la iglesia, incluido el coro, como se recoge en 1462, cuando se contrató uno nuevo (fol. 230v.).

62 Libro de Cuentas 1458-1475, 17 de mayo de 1464, ACS, C-201, fol. 124v.

${ }^{63}$ De Lecea, 1889: 225.

64 Cortón, 1997: 115, 121, 124 y 136 respectivamente.

${ }^{65}$ Cortón, 1997: 159.

${ }^{66}$ Libro de cuentas 1542-1562, 28 de septiembre de 1558, ACS, C-230, s.f.

${ }^{67}$ Libro de cuentas 1542-1562, 20 de septiembre de 1558, ACS, C-230, s.f.

68 Ruiz, 1994: 38. 


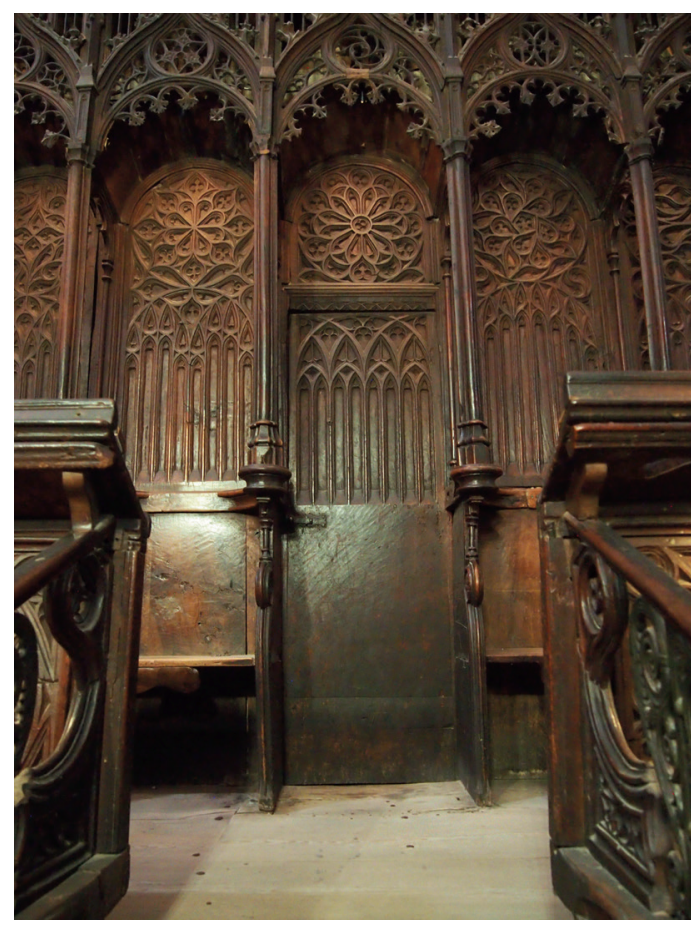

Fig. 10. Sillería de la Catedral de Segovia. Puerta del lado del Evangelio. Fotografía de los autores.

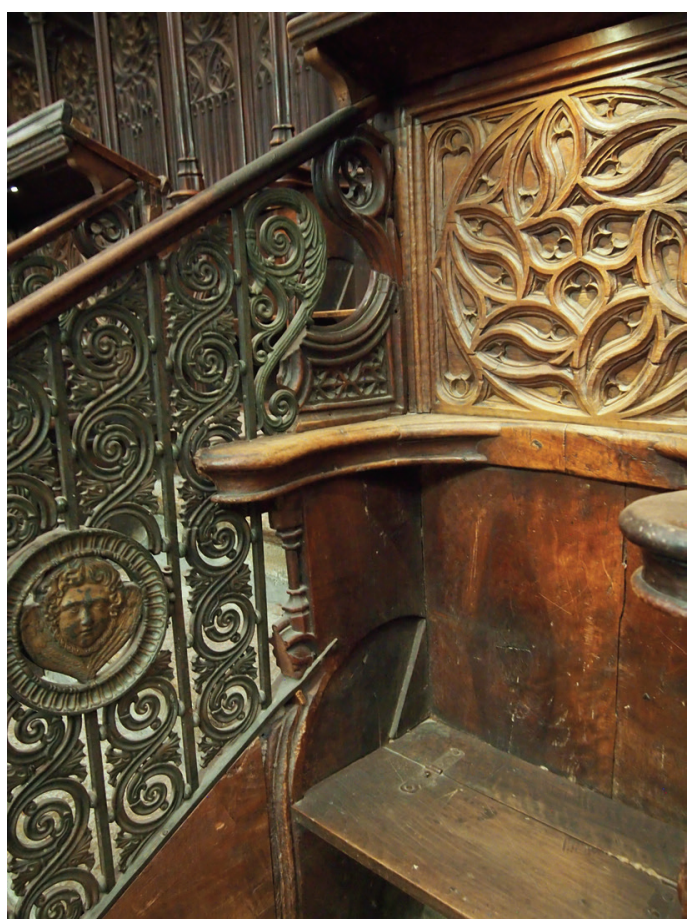

Fig. 11. Sillería de la Catedral de Segovia. Escalera. Fotografía de los autores.

pal-, y 53 bajos, de las que restan 51 altas y 41 bajas del conjunto gótico, dos rincones altos y bajos, dos puertas en la sillería alta y cuatro escaleras de acceso a la misma.

\section{El perfecto y completo ejemplo de su tipología}

Los cuarenta y un estalos bajos y cincuenta y uno altos de la sillería gótica se distribuían en dos coros, el del deán y el del obispo, aunque no tenemos constancia documental de cómo, con la excepción de los reales, que se situaban en los cabos, es decir, cerrando ambos extremos del coro alto por el lado oriental, como se encuentran hoy (fig. 6). Como se ha comentado hay menos información sobre el estalo episcopal, que hoy se encuentra en el centro del lado occidental, cerrando este, ubicación que debió tener desde el principio. Como se ha visto, en este mismo lado se abrían dos puertas que permitían el acceso al interior del coro a través del trascoro; es probable que hubiera otras dos en los lados septentrional y meridional (fig. 10), ya que las cuatro escaleras hoy existentes son similares y por su estructura y talla podrían pertenecer perfectamente al conjunto original, a pesar de que han sido mutiladas para encajar las barandillas metálicas que se añadirían durante el traslado, rompiendo en la mayoría la parte inferior de la crosa (fig. 11).

La obra guarda evidentes similitudes con la sillería de la catedral palentina, obra del primer cuarto del siglo XV. El diseño de los estalos bajos es el mismo, e igualmente lo son algunos de sus elementos, como los pomos que individualizan cada dosel, los apoyamanos circulares decorados con relieves en ambos lados o los remates de los cabos y escaleras en volutas rematadas en círculos calados. Mayores diferencias pueden verse en la composición de los estalos altos, que coincide sin embargo en un elemento de inercia, la separación de cada estalo por medio de baldaquinos que se apoyan en esbeltos pilares: frente a la mayor sobriedad de los desornamentados dorsales palentinos y la simplicidad de los gabletes triangulares solo animados por la presencia de la heráldica, en Segovia los dorsales se ornan completamente con tracerías góticas que, sobre 


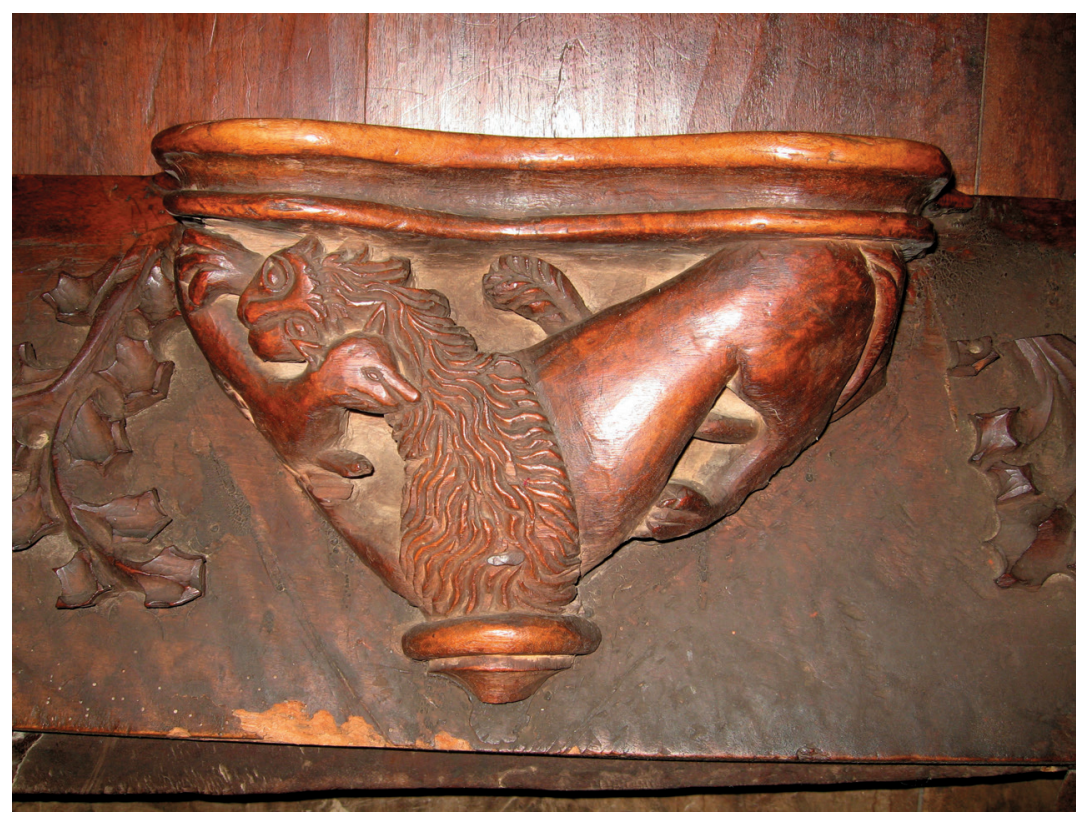

Fig. 12. Sillería de la Catedral de Segovia. Misericordia del estalo del rey. Fotografía de los autores.

la combinación del círculo sobre arcuaciones ojivales que se subdividen en su interior, generan motivos siempre diferentes, y en los doseles encontramos ya arcos conopiales que, si bien repiten un mismo tipo de tracería vegetal en el intradós, calan su motivo central, al igual que su fondo de lancetas. Las misericordias de ambos conjuntos, aún poco aprovechadas desde el punto de vista figurativo, presentan un mismo módulo alargado, de escaso desarrollo ornamental en el cuerpo central, apoyado sobre una similar base arquitectónica y expandiendo sus motivos vegetales por el espacio del asiento; solo las de los estalos reales muestran un mejor aprovechamiento de las posibilidades del soporte de talla figurada, con sendas figuras de leones — cazando un zorro en la del rey (fig. 12), rugiendo en la de la reina-, que pueden entenderse en clave heráldica.

Similitudes claras entre ambos conjuntos podemos ver también en los motivos utilizados en las partes talladas — dorsales, coronamiento, apoyamanos-. Círculos, triángulos, rombos se rellenan en su interior de líneas flamígeras que se combinan de maneras absolutamente variadas, recogiendo motivos típicamente góticos como los cuadrilóbulos, las rosas o las lancetas y arcos trifoliados que también podemos encontrar en la tracería de las ventanas y en otras microarquitecturas. La combinación de elementos circulares con tracería interna a manera de pequeños rosetones y de arcuaciones en módulos que se van subdividiendo en su interior nos remiten a modelos de diseño arquitectónico que podemos encontrar no solo en la arquitectura, sino también en la orfebrería coetánea. No podemos perder de vista la concepción del coro como espacio especialmente sacralizado dentro del templo, cerrado y defendido, a modo de fortaleza, por sus muros laterales; es decir, una duplicación del templo en el interior de este, por lo que estas referencias arquitectónicas, familiares al clero usuario de este espacio, son perfectamente adecuadas, con el valor añadido de permitir la fantasía y el preciosismo que no eran posibles en la construcción en piedra.

La diferenciación del diseño entre estalos y niveles proporcionaba, por otra parte, la individualización espacial y la jerarquización que regulaba el funcionamiento interno del clero catedralicio y que siempre tuvieron una gran importancia en los estalos, cuya composición y talla debían mostrar a los capitulares su lugar y relevancia en la institución eclesiástica — estalos altos para las dignidades y canónigos y bajos para racioneros, capellanes y otros religiosos de menor categoríaEsta diferenciación, ya clara en los estalos catedralicios de Palencia y Segovia, sería el punto de partida de las modificaciones fundamentales que introduce un conjunto hecho según el modelo de estas, la sillería de la catedral de León, que inaugura una tendencia de enorme éxito posterior al 
introducir la talla figurada en los respaldos de ambas sillas ${ }^{69}$. De este modo los estalos segovianos se convirtieron no solo en el mejor ejemplo de la fase de madurez del modelo de sillería anicónica, que tendría su continuidad hasta época moderna, sino que constituirían también el punto de partida del modelo de sillería figurativa que podemos encontrar hasta el siglo XVIII ${ }^{70}$.

Además, la inclusión de los estalos episcopal y reales como sillas diferenciadas pero perfectamente integradas en el conjunto coral se hizo igualmente de un modo novedoso y resuelto con sutileza, lo que supondrá que otros conjuntos posteriores asuman esta misma configuración como influencia directa o indirecta de la obra segoviana. Si la distinción de estos estalos con respecto al resto podía resolverse fácilmente con la ampliación de sus medidas o con el uso de recursos como el dorado y el color y elementos identificativos como la heráldica, u otros más propios de los conjuntos corales como las crosas de remate o los baldaquinos, su ubicación dentro de un conjunto de sillas corridas con las que no debían confundirse supuso un reto importante, entre otras cosas porque tampoco debía haber confusión entre uno y otros al aludir a poderes diferentes con una distinta presencia dentro del templo.

El obispo, como cabeza de la diócesis, tenía desde luego un lugar destacado en el coro, que solía ser uno de los extremos del mismo, bien en la parte más cercana al altar, bien en la más cercana a la gran puerta de acceso que solía abrirse en el lado occidental. En la sillería segoviana, al cerrarse este último, su centro era la ubicación perfecta para la silla del obispo, lo que liberaba los extremos meridional y septentrional para las sillas reales, en una configuración que seguirán más tarde conjuntos catedralicios como los ya mencionados de Zamora y Plasencia. En estos dos últimos ejemplos la monarquía bicéfala de Isabel y Fernando justifica evidentemente la presencia de dos estalos reales ${ }^{71}$, lo que no estaba tan claro en Segovia con Enrique y Juana, ni siquiera aunque esta colaborase con sus regalos al acondicionamiento del espacio coral; solo una cuestión de organización del conjunto explica la presencia de ambos estalos regios, que de este modo ven doblemente honrada la dignidad monárquica sin disminuir la mayor relevancia del obispo en su trono, alineado con el altar mayor. En este sentido debemos entender igualmente que, frente a las referencias directas al rey Enrique IV en su silla, en la de la reina los motivos figurativos se refieran siempre a la Corona en general y al reino castellano de manera específica ${ }^{72}$.

La nueva sillería segoviana se convierte así, por voluntad de su cabildo y con una muy probable y directa intervención de sus prelados - Villaescusa y Arias Dávila-, y la participación económica del rey Enrique IV - quien tiene una presencia muy significativa en ella- en una obra que, partiendo de la tradición de los conjuntos anicónicos castellanos de los siglos anteriores, convierte este concepto central en factor de renovación y modernización de los estalos catedralicios, convirtiéndose en pieza fundamental de un modelo con una larga pervivencia entre las sillerías corales hispanas del gótico final y con una importante proyección durante toda la época moderna.

\section{BIBLIOGRAFÍA}

Alonso Ruiz, B. (2015): "El coro y el trascoro de la catedral de Palencia. Arquitectos y entalladores del tardogótico". En: Choir Stalls in Architecture and Architecture in Choir Stalls. Newcastle upon Tyne: Cambridge Scholar Publishing, pp. 234-249.

Bartolomé Herrero, B. (2004): “Juan Arias Dávila, obispo de Segovia”. En: Juan Parix, primer impresor en España. Burgos: Instituto Castellano y Leonés de la Lengua, pp. 203-224.

${ }^{69}$ El cabildo catedralicio leonés envió al primer maestro de las sillas, Maestro Enrique, a visitar estos conjuntos para tomarlos como modelo para los estalos leoneses, que seguramente en un primer momento reprodujeron lo visto sobre todo en Segovia, que suponía realmente la vanguardia de la tipología en ese momento y donde debió ver las sillas recién instaladas o en fase de ensamblado. Teijeira, 2018b.

${ }^{70}$ Pelayo Quintero Atauri basó su intento de catalogación de las sillerías corales españolas en su clasificación en estos dos grandes grupos, con y sin imaginería. Quintero, 1908.

71 Ver nota 21.

72 Teijeira/Villaseñor, 2018. 
Colmenares, D. de (1637): Historia de la insigne ciudad de Segovia y compendio de las historias de Castilla. Segovia: Diego Díez impresor.

Cortón de las Heras, M. T. (1997): La construcción de la Catedral de Segovia (1525-1607). Segovia: Caja de Ahorros y Monte de Piedad.

Duro Peña, E. (1964): "Las antiguas dignidades de la catedral de Orense". En: Anuario de Estudios Medievales, 1, Barcelona, pp. 289-332.

Lecea, C. de (1889): “Memorial histórico de Segovia escrito por don Juan de Pantigoso en 1523”. En: Boletín de la Real Academia de la Historia, 14, Madrid, pp. 214-261.

Le Flem, J. P. (1970): "La première version castillane du testament de Don Juan Arias Dávila, évêque de Ségovie". En: Estudios Segovianos, 64, Segovia, pp. 17-46.

García García, A. (1993): Synodicon Hispanum. VI. Ávila y Segovia. Madrid: BAC.

Heim, D. (2012): "Las intarsias de la sillería del coro de Plasencia: influencia italiana temprana en el núcleo artístico toledano". En: Anales de Historia del Arte, 22. Número especial, Madrid, pp. 59-84.

López Díez, M. (1998): "Las artes en el siglo XV. El mecenazgo de los Arias Dávila”. En: Segovia en el siglo XV. Arias Dávila: Obispo y mecenas. Salamanca: Universidad Pontificia de Salamanca, pp.273-296.

López Díez, M. (2006): Los Trastámara en Segovia. Juan Guas, maestro de obras reales. Segovia: Obra cultural Caja Segovia.

Mogollón Cano-Cortés, P. / Pizarro Gómez, F. J. (1991): La Sillería de coro de la catedral de Plasencia. Cáceres: Universidad de Extremadura.

Navascués Palacio, P. (2013): "Sobre el coro de la catedral de Segovia". En: Segovia, su catedral y su arquitectura. Ensayos en homenaje a José Antonio Ruiz Hernando. Madrid: Instituto Juan de Herrera, pp.159-171.

Quintero Atauri, P. (1908): Sillas de coro. Noticias de las más importantes que se conservan en España. Madrid: Estanislao Mestre.

Ruiz Hernando, J. A. (1994): La Catedral de Segovia. León: Edilesa.

Sanz y Sanz, H. (1967): "Bosquejo histórico de dos catedrales". En: Estudios Segovianos, XIX, Segovia, 161-205.

Sanz y Sanz, H. (1988): Catálogo de la Colección diplomática medieval del Archivo catedralicio de Segovia. Segovia: Obra cultural Caja Segovia.

Soto Cano, M. (2005): "El traslado de la catedral de Segovia. Propuestas y actuaciones entre la segunda mitad del siglo XV y 1523”. En: Carrero Santamaría, E. y Rico Camps, D. (coords.): Catedral y ciudad en la Península Ibérica. Murcia: Nausicaa, pp. 215-242.

Teijeira Pablos, M. D. (1993): La influencia del modelo gótico flamenco en León. La sillería de coro catedralicia. León: Universidad de León.

Teijeira Pablos, M. D. (1996): Juan de Bruselas y la sillería coral de la catedral de Zamora. Zamora: Instituto de Estudios Zamoranos "Florián de Ocampo".

Teijeira Pablos, M. D. (2001): "El trono episcopal de la catedral de Palencia. Un antecedente de los programas tipológicos en las sillerías corales góticas". En: Archivo Español de Arte, 74, 294, Madrid, pp.171-179.

Teijeira Pablos, M. D. (2018a), "The Last Service of a Prelate to his Cathedral. The Impact of Episcopal Wills on the Artistic Development of the Castilian Sees in Late Gothic Times". En: Herráez, M. V. et al. (eds.): Obispos y Catedrales. Arte en la Castilla bajomedieval. Berna: Peter Lang, pp.259-288.

Teijeira Pablos, M. D. (2018b): "Obispos, cabildos y tallistas en la transformación de las sillerías del tardogótico hispano. A propósito de los estalos del Museo de la Catedral de León”. En: Actas del XXII Congreso del CEHA. Burgos, en prensa.

Teijeira Pablos, M. D. / Villaseñor Sebastián, F. (2018): "Bishop Juan Arias Dávila and King Henry IV in Segovia Cathedral. A fake stalls patron?". En: Choir Stalls and their Patrons. En prensa.

Villaseñor Sebastián, F. (2009): El libro iluminado en Castilla durante la segunda mitad del siglo XV. Burgos: Instituto Castellano y Leonés de la Lengua.

Villaseñor Sebastián, F. (2018): "The Artistic Promotion of Lope de Barrientos: Bishop of Segovia, Ávila and Cuenca". En: Herráez, M. V. et al. (eds.): Obispos y Catedrales. Arte en la Castilla bajomedieval. Berna: Peter Lang, pp. 183-220.

Yarza Luaces, J. (1989): "Dos mentalidades, dos actitudes ante las formas artísticas: Diego de Deza y Juan Rodríguez de Fonseca”. En: Jornadas sobre la Catedral de Palencia. Palencia: Diputación Provincial de Palencia, 1989, pp. 109-112.

Fecha de recepción: 22-XI-2018

Fecha de aceptación: 11-II-2019 